\title{
Intake of dietary fat and fat subtypes and risk of premenstrual syndrome in the Nurses' Health Study II
}

\author{
Serena C. Houghton ${ }^{1 *}$, JoAnn E. Manson ${ }^{2,3,4}$, Brian W. Whitcomb ${ }^{1}$, Susan E. Hankinson ${ }^{1,2}$, Lisa M. Troy ${ }^{5}$, \\ Carol Bigelow ${ }^{1}$ and Elizabeth R. Bertone-Johnson ${ }^{1}$ \\ ${ }^{1}$ Department of Biostatistics and Epidemiology, University of Massachusetts, Amberst, MA 01003, USA \\ ${ }^{2}$ Channing Division of Network Medicine, Brigham and Women's Hospital, Boston, MA O2115, USA \\ ${ }^{3}$ Harvard Medical School, Division of Preventive Medicine, Brigham and Women's Hospital, Boston, MA O2115, USA \\ ${ }^{4}$ Department of Epidemiology, Harvard T.H. Chan School of Public Health, Boston, MA 02115, USA \\ ${ }^{5}$ Department of Nutrition, University of Massachusetts, Amberst, MA 01003, USA
}

(Submitted 17 May 2017 - Final revision received 24 August 2017 - Accepted 8 September 2017)

\section{Abstract}

Approximately $8-20 \%$ of reproductive-aged women experience premenstrual syndrome (PMS), substantially impacting quality of life. Women with PMS are encouraged to reduce fat intake to alleviate symptoms; however, its role in PMS development is unclear. We evaluated the association between dietary fat intake and PMS development among a subset of the prospective Nurses' Health Study II cohort. We compared 1257 women reporting clinician-diagnosed PMS, confirmed by premenstrual symptom questionnaire and 2463 matched controls with no or minimal premenstrual symptoms. Intakes of total fat, subtypes and fatty acids were assessed via FFQ. After adjustment for age, BMI, smoking, $\mathrm{Ca}$ and other factors, intakes of total fat, MUFA, PUFA and trans-fat measured 2-4 years before were not associated with PMS. High SFA intake was associated with lower PMS risk (relative risk (RR) quintile 5 (median $=28 \cdot 1 \mathrm{~g} / \mathrm{d}) v$. quintile $1(\mathrm{median}=$ $15.1 \mathrm{~g} / \mathrm{d})=0.75 ; 95 \%$ CI $\left.0.58,0.98 ; P_{\text {trend }}=0.07\right)$. This association was largely attributable to stearic acid intake, with women in the highest quintile (median $=7.4 \mathrm{~g} / \mathrm{d}$ ) having a RR of $0.75 v$. those with the lowest intake (median $=3.7 \mathrm{~g} / \mathrm{d})\left(95 \%\right.$ CI $\left.0.57,0.97 ; P_{\text {trend }}=0 \cdot 03\right)$. Individual PUFA and MUFA, including $n-3$ fatty acids, were not associated with risk. Overall, fat intake was not associated with higher PMS risk. High intake of stearic acid may be associated with a lower risk of developing PMS. Additional prospective research is needed to confirm this finding.

\section{Key words: Premenstrual syndrome: Dietary fat: Fatty acids: Epidemiology: Prospective studies}

Premenstrual syndrome (PMS) is a cyclical late luteal phase disorder of the menstrual cycle whereby the daily functioning of women is affected by emotional and physical symptoms substantially interfering with her quality of life ${ }^{(1,2)}$. It is estimated that approximately 8-20\% of reproductive-aged women meet clinical diagnostic criteria for PMS ${ }^{(3,4)}$. Several treatment options exist (e.g. oral contraceptives, gonadotropin-releasing hormone agonists, antidepressants); however, these may have side effects and efficacy is relatively low ${ }^{(5)}$. Furthermore, emerging research suggests that PMS may be an early sentinel for risk of hypertension $^{(6)}$. Thus, it is important to identify modifiable risk factors to prevent the initial development of PMS, particularly those that are feasible to implement, such as dietary changes.

The American Congress of Obstetricians and Gynecologists recommends reducing fat intake to treat $\mathrm{PMS}^{(7)}$. However, evidence supporting these recommendations is limited, and it is unclear whether they apply to the prevention of PMS development ${ }^{(8)}$. A small number of retrospective studies have reported inconsistent relationships between premenstrual symptoms and consumption of fats ${ }^{(9,10)}$. Among retrospective studies, because of issues related to establishing temporality, it is unknown whether increased fat and fatty acid intake precedes the development of PMS. In addition, little attention has been given to specific types of fat, with most studies evaluating either total fat ${ }^{(9,10)}$ or supplementation with $n-3^{(11-13)}$, $\gamma$-linolenic acid $^{(14)}$ and evening primrose oil ${ }^{(15)}$.

Although the aetiological cause of PMS has yet to be elucidated, suggestions include chronic inflammation and alterations in hormones. Dietary fats may affect a woman's cytokine and hormone levels ${ }^{(8)}$. Dietary fat and SFA have been shown to act as pro-inflammatory factors increasing C-reactive protein (CRP) concentrations $^{(16,17)}$, whereas the unsaturated $n-3$ fatty acids have been shown to act as anti-inflammatory factors decreasing CRP and IL-6 concentrations ${ }^{(18-20)}$. Higher CRP and other

Abbreviations: NHS2, Nurses' Health Study II; PMS, premenstrual syndrome; RR, relative risk.

* Corresponding author: S. C. Houghton, fax +1 413545 1645, email shoughto@schoolph.umass.edu 
inflammatory cytokine levels have been linked to $\mathrm{PMS}^{(21)}$ and premenstrual symptoms ${ }^{(22-24)}$. Second, higher intakes of SFA are associated with higher plasma total and free estradiol levels and lower concentrations of luteinizing hormone among premenopausal women ${ }^{(25)}$. Hormone levels have been long implicated in the aetiology of PMS due to its cyclical nature of symptoms ${ }^{(26)}$.

To our knowledge, no previous study has prospectively evaluated whether total fat, fat subtypes or individual fatty acid intake is associated with risk of developing PMS. Therefore based on prior epidemiological studies and suggested biological pathways, we evaluated the hypothesis that higher intakes of total, SFA and trans-fat and lower intakes of unsaturated fats and fatty acids were related to increased PMS risk, in the Nurses' Health Study II (NHS2) PMS Sub-Study, a case-control study nested within the prospective NHS2.

\section{Methods}

\section{Study population}

The NHS2 is a large prospective cohort of 116429 US female registered nurses, aged 25-42 years in 1989, that has assessed demographics, health-related behaviours, diet, and medical history biennially and diet quadrennially for over 25 years ${ }^{(27)}$. Response rates have been $\geq 89 \%$ for all questionnaire cycles. The original NHS2 study protocol was approved by the Institutional Review Board at Brigham and Women's Hospital in Boston, Massachusetts.

\section{Classification of premenstrual syndrome cases and controls}

The NHS2 PMS Sub-Study has been described previously ${ }^{(27,28)}$. In brief, we identified all NHS2 members who had not reported a diagnosis of PMS by a clinician in either 1989 or 1991 and thus were at risk of developing PMS. Premenopausal women reporting a new clinician-made diagnosis of PMS during the follow-up period in 1991-2005 were selected as potential cases ( $n$ 4108) with the diagnosis year assigned as their reference year. Potential controls were randomly selected from women who did not report a diagnosis of PMS from 1991-2005 ( $n$ 3248). These women were randomly assigned a reference year (1991-2005) corresponding to the cases' diagnosis years, and then were frequency matched to cases on age and reference years. Women who had reported a history of cancer (other than non-melanoma skin cancer), endometriosis, extremely irregular menstrual cycles, infertility, hysterectomy or menopause before their assigned reference year were excluded to reduce likelihood of inclusion of women with symptoms similar to PMS due to other conditions. In addition, because of our interest in diet, those with implausible energetic intakes (i.e. those below $2092 \mathrm{~kJ} / \mathrm{d}$ ( $500 \mathrm{kcal} / \mathrm{d}$ ) and above $14644 \mathrm{~kJ} / \mathrm{d}$ $(3500 \mathrm{kcal} / \mathrm{d}))$ were also excluded.

All potential cases and controls were sent a modified version of the Calendar of Premenstrual Experiences questionnaire ${ }^{(28,29)}$ in 2003 for the 1991-2001 follow-up cycles and then in 2007 for the 2003-2005 follow-up cycles, that assessed the occurrence of twenty-six physical and affective symptoms in the 2 years before their specific reference year, the timing of symptoms and the impact of symptoms on several domains of daily functioning. Of those that were sent the questionnaire, $87 \%$ of the potential cases ( $n$ 3579) and $95 \%$ of the potential controls ( $n$ 3087) returned a completed questionnaire. We used the responses to the premenstrual questionnaire to confirm potential cases as meeting clinical diagnostic guidelines and potential controls as having no premenstrual symptoms.

There were 1257 women who met clinical diagnostic guidelines for PMS. Specifically, the cases reported: (1) $\geq 1$ physical and $\geq 1$ affective menstrual symptoms; (2) overall symptom severity of 'moderate' or 'severe' or 'moderate' or 'severe' effect of symptoms on at least one life activity or relationship domain; (3) symptoms began $\leq 14 \mathrm{~d}$ before start of menses; (4) symptoms ended $\leq 4 \mathrm{~d}$ after start of menses; and (5) symptoms were not present in week after menses ended ${ }^{(27)}$.

Women who had no or minimal symptoms that did not impact daily function domains were verified as controls (n 2463). Specifically they: (1) confirmed no PMS diagnosis; (2) reported either no menstrual symptoms, or an overall symptom severity of 'minimal' or 'mild'; and (3) reported either 'no effect' or 'mild' effect of symptoms on all life activities and relationship domains ${ }^{(27)}$.

Participants who did not meet these definitions were excluded from further analysis. This allowed for a comparison of women at the two extreme ends of the spectrum of premenstrual symptom experience and reduced the likelihood of misclassification of cases as controls and vice-versa. Our approach for identifying PMS cases and controls has been validated previously and found to be comparable with prospective charting of symptoms ${ }^{(27)}$.

\section{Assessment of fat intake}

In the NHS2, a 131-item semi-quantitative FFQ was first given in 1991 and then repeated every four years thereafter ${ }^{(30)}$. We used food intake information reported on the FFQ to assess the intake of total fat, SFA, MUFA, PUFA, trans-fat, dairy fat, animal fat, vegetable fat, total $n-3$, total $n-6$, the ratio of $n-6: n-3$, and specific fatty acids hypothesised to play a role in PMS development including stearic acid (18:0), oleic acid (18:1n-9), arachidonic acid $(20: 4 n-6)$, linoleic acid (18:2n-6), conjugated linoleic acid (cis-9, trans-11 18:2), linolenic acid (18:3), EPA $(20: 5 n-3)$, and DHA (22:6n-3). The FFQ included food high in fat such as red meat, chicken with skin, bacon, processed meats, fish, eggs, butter, margarine, whole milk, cheese, ice cream, French fries, potato chips, peanut butter and nuts. In addition, participants were asked about the types of fat used for frying and baking and whether fish oil or cod liver oil supplements are used. Participants indicated the frequency with which they consumed a specific portion size of each food item, with a nine-option range from 'never or less than once per month' to ' 6 or more times per d'. To calculate each participant's dietary fat intakes, the portion size of each food item was multiplied by the indicated frequency of consumption and fat content and then summed across all foods. The fat and fatty acid content of each food is based on the Harvard University Food Composition Table ${ }^{(31)}$, which is updated every 4 years based on information from the US Department of Agriculture, food 
manufacturers, academic publications and direct analyses of fatty acids (e.g. trans-fat) in commonly used foods to reflect changes in manufacturing and food supply over time. Dairy fat is a subset of animal fat (i.e. animal fat also includes dairy fats), which includes all fat from the foods in the 'Dairy Foods' section on the FFQ except for margarine and non-dairy whitener and fat from the dairy products used as ingredients in other FFQ items. Nutrient intakes were adjusted for total energy using the residual method ${ }^{(30)}$.

The reproducibility and validity of similar FFQs have been evaluated previously in the NHS ${ }^{(30,32-34)}$. The energy adjusted correlation between intakes reported by FFQ and mean intake measured via two 1 -week diet records in 1986 ( $n$ 191) was 0.51 , $0.59,0.41$ and 0.51 for total fat, SFA, PUFA and MUFA, respectively ${ }^{(30)}$. Further, dietary intake correlated with subcutaneous adipose tissue aspirate levels of PUFA $(r 0.37), n-3$ marine fatty acids $(r 0.48)$ and trans-fatty acids $(r 0.51)$ but not serum SFA or MUFA levels ( $r \quad 0.16$ and 0.07 respectively) in a study of 115 postmenopausal US women using a similar $\mathrm{FFQ}^{(32)}$.

Primary analyses used the most recent FFQ that preceded the reference year (i.e. 2-4 years). For example, if a woman was diagnosed with PMS in 1999 then information from the 1995 FFQ was used. We additionally examined intakes from the baseline (1991) FFQ, a more distal exposure. Dietary information from 3638 Sub-Study participants was available for analyses of intake 2-4 years before a woman's reference year and for 3660 women for analyses of intake at baseline in 1991 .

\section{Assessment of covariates}

We considered as covariates variables associated with PMS in our population. Height and menstrual cycle characteristics were assessed on the 1989 questionnaire. History of depression and antidepressant use were assessed on the premenstrual questionnaire. Childhood trauma was assessed in 2001 on a separate questionnaire $^{(35)}$. Other factors were collected on each biennial questionnaire and included age, smoking status, weight (used to calculate BMI in $\mathrm{kg} / \mathrm{m}^{2}$ ), pregnancy history and oral contraceptive use. Lastly, other nutrients such as B-vitamins, Fe and $\mathrm{Ca}$ were assessed by FFQ and were calculated using similar methods as fat intake.

\section{Statistical analysis}

Age-adjusted baseline characteristics of PMS cases and controls were compared using generalised linear modelling. We used unconditional logistic regression models to estimate relative risks (RR) of PMS for women across quintiles of fat intake at 2-4 years before each woman's reference year and calculated 95\% CI comparing the risk of PMS in each of the four highest quintiles compared with the lowest quintile adjusting for age. Multivariable logistic regression models additionally adjusted for reference year, age in 1991, age at menarche, calculated BMI (weight $(\mathrm{kg}) /$ height $\left(\mathrm{m}^{2}\right)$ ), physical activity, oral contraceptives, parity (pregnancies lasting $\geq 6$ months), smoking (pack-years), previous use of antidepressants, significant childhood trauma, previous diagnosis of depression, total intake of vitamins $\mathrm{B}_{6}, \mathrm{~B}_{1}$, $\mathrm{Fe}$ and $\mathrm{Ca} 2-4$ years before the reference year. Secondary analyses were run using the intake at baseline to assess the possibility of latent effects adjusting for covariates measured at baseline in 1991. Additional multivariable models also adjusted subtypes of fat for the effect of other subtypes (e.g. SFA was adjusted for MUFA, PUFA and trans-fat) and each source of fat was adjusted for the other sources (e.g. dairy fat was also adjusted for vegetable and animal fat). The Mantel extension test for trend was used to examine the presence of linear trend across quintiles, modelling the median of each quintile as a continuous variable.

We further assessed whether the relationship of dietary fat and PMS varied by age at reference year $(<40 v . \geq 40$ years $)$ and smoking (past/never $v$. current) via stratified analyses. The multiplicative interaction terms were evaluated using likelihood ratio test, where the interaction terms were calculated as the products of a binary stratification factor and indicators of the macronutrient quintile. In a sub-analysis, we also restricted analyses to non-oral contraceptive users.

SAS 9.3 (SAS Institute Inc.) for UNIX was used for all analyses. Two-sided $P<0.05$ were considered statistically significant for all analyses.

\section{Results}

Baseline characteristics of PMS cases and controls are shown in Table 1. Cases were heavier at baseline and age 18 years, had a slightly earlier age at menarche, and had higher history of oral contraceptive use, smoking, significant childhood trauma, depression and antidepressant use. In addition, cases on average consumed less vitamin $\mathrm{D}, \mathrm{Ca}$ and higher vitamins $\mathrm{B}_{6}$ and $\mathrm{B}_{12}$ than controls.

Table 2 presents age-adjusted and multivariate-adjusted RR and $95 \%$ CI for types of fats consumed 2-4 years before the reference year and the risk of developing PMS. In analyses adjusted only for age, total fat, PUFA and MUFA were each positively associated with risk of developing PMS ( $P_{\text {trend }} \leq 0.05$ for all). However, after controlling for BMI, smoking and additional covariates, these positive associations were attenuated and no longer significant. The strongest confounders of the fat and PMS relation were BMI, smoking, and vitamin D. In multivariable adjusted models (model 1), high SFA intake was inversely associated with risk of PMS (RR quintile $5 v$. quintile $1=0.75 ; 95 \%$ CI $0.58,0.98)$. When the models were additionally adjusted for other fats (model 2), SFA estimates were slightly stronger (RR quintile $5 v$. quintile $1=0 \cdot 63 ; 95 \% \mathrm{CI}$ $0.44,0.92)$. The estimates for other subtypes of fats were largely unchanged and interpretations did not change.

Table 3 shows results from models assessing risk of PMS related to sources of fats. Intakes of vegetable and dairy fats were unrelated to PMS risk, with estimates for all quintiles approximately equal to 1 . High animal fat intake was related to a non-significant lower risk of PMS in age-adjusted $\left(P_{\text {trend }}=0.53\right)$ and multivariable adjusted (model 1) models $\left(P_{\text {trend }}=0 \cdot 17\right.$ ). Additional adjustment for the other sources of fat (model 2) did not affect the interpretations of any of the estimates.

Results for models of fatty acid intake and PMS risk are presented in Table 4. Stearic acid, a SFA, was inversely associated 
Table 1. Age-standardised characteristics of premenstrual syndrome (PMS) cases and controls at baseline ( $n$ 3660): Nurses' Health Study II PMS sub-study, 1991-2005

(Mean values and standard deviations; percentages)

\begin{tabular}{|c|c|c|c|c|c|}
\hline \multirow[b]{2}{*}{ Characteristics* $^{*}$} & \multicolumn{2}{|c|}{$\begin{array}{c}\text { Cases } \\
(n 1234)\end{array}$} & \multicolumn{2}{|c|}{$\begin{array}{l}\text { Controls } \\
(n \text { 2426) }\end{array}$} & \multirow[b]{2}{*}{$P \dagger$} \\
\hline & Mean & SD & Mean & SD & \\
\hline Age (years) & $33 \cdot 9$ & $4 \cdot 2$ & 34.5 & 3.9 & $<0.0001$ \\
\hline \multicolumn{6}{|l|}{ BMI $\left(\mathrm{kg} / \mathrm{m}^{2}\right)$} \\
\hline At baseline (1991) & $24 \cdot 6$ & $5 \cdot 2$ & $23 \cdot 7$ & 4.7 & $<0.0001$ \\
\hline At age 18 years & 21.4 & $3 \cdot 3$ & $21 \cdot 1$ & $3 \cdot 1$ & 0.02 \\
\hline Age at menarche (years) & $12 \cdot 4$ & 1.4 & $12 \cdot 5$ & 1.4 & 0.05 \\
\hline Age at first birth (years) $\ddagger$ & $25 \cdot 9$ & 3.9 & $26 \cdot 1$ & $3 \cdot 7$ & $0 \cdot 10$ \\
\hline Number of full-term pregnancies ( $\geq 6$ months) & 1.6 & $1 \cdot 2$ & 1.6 & 1.2 & 0.36 \\
\hline Physical activity (METs/week) & $22 \cdot 9$ & $60 \cdot 2$ & $23 \cdot 6$ & $55 \cdot 6$ & 0.74 \\
\hline Pack-years of cigarette smoking & $8 \cdot 3$ & 64.7 & 4.8 & $50 \cdot 2$ & 0.09 \\
\hline Alcohol intake (g/d) & $3 \cdot 1$ & 6.5 & $3 \cdot 1$ & $5 \cdot 7$ & 0.99 \\
\hline Total energy intake $(\mathrm{kJ} / \mathrm{d})$ & 7640 & 2247 & 7586 & 2176 & 0.62 \\
\hline Total energy intake $(\mathrm{kcal} / \mathrm{d})$ & 1826 & 537 & 1813 & 520 & 0.62 \\
\hline Vitamin D intake food sources $(\mu \mathrm{g} / \mathrm{d}) \S$ & $6 \cdot 4$ & $3 \cdot 0$ & $6 \cdot 7$ & $3 \cdot 1$ & 0.01 \\
\hline Total vitamin $B_{6}$ intake $(\mathrm{mg} / \mathrm{d}) \S$ & 8.6 & $26 \cdot 3$ & $5 \cdot 8$ & $15 \cdot 6$ & $<0.0001$ \\
\hline Total vitamin $B_{12}$ intake $(\mathrm{mg} / \mathrm{d}) \S$ & $10 \cdot 1$ & $14 \cdot 2$ & 9.4 & 8.5 & 0.04 \\
\hline Total thiamine intake $(\mathrm{mg} / \mathrm{d}) \S$ & 3.6 & $8 \cdot 2$ & $3 \cdot 2$ & $6 \cdot 0$ & 0.09 \\
\hline Total riboflavin intake $(\mathrm{mg} / \mathrm{d}) \S$ & $4 \cdot 1$ & $8 \cdot 2$ & $3 \cdot 6$ & $5 \cdot 7$ & 0.07 \\
\hline Total Fe intake $(\mathrm{mg} / \mathrm{d}) \S$ & 24.9 & $23 \cdot 3$ & $25 \cdot 8$ & $24 \cdot 8$ & 0.35 \\
\hline Total $\mathrm{Zn}$ intake $(\mathrm{mg} / \mathrm{d}) \S$ & $15 \cdot 9$ & $10 \cdot 7$ & $15 \cdot 7$ & $10 \cdot 3$ & 0.59 \\
\hline Total $\mathrm{K}$ intake $(\mathrm{mg} / \mathrm{d}) \S$ & 2925 & 499 & 2897 & 501 & 0.17 \\
\hline Total Ca intake $(\mathrm{mg} / \mathrm{d}) \S$ & 1030 & 403 & 1063 & 421 & 0.03 \\
\hline History of tubal ligation (\%) & & & & & 0.66 \\
\hline \multicolumn{6}{|l|}{ Oral contraceptive use (\%) } \\
\hline Ever & \multicolumn{2}{|c|}{85} & \multicolumn{2}{|c|}{77} & $<0.0001$ \\
\hline Current & \multicolumn{2}{|c|}{12} & \multicolumn{2}{|c|}{11} & 0.33 \\
\hline Duration $>4$ years & \multicolumn{2}{|c|}{43} & \multicolumn{2}{|c|}{37} & 0.001 \\
\hline \multicolumn{6}{|l|}{ Smoking status (\%) } \\
\hline Current & \multicolumn{2}{|c|}{13} & \multicolumn{2}{|c|}{7} & $<0.0001$ \\
\hline Past & \multicolumn{2}{|c|}{27} & \multicolumn{2}{|c|}{17} & $<0.0001$ \\
\hline Previously diagnosed with depression (\%) & \multicolumn{2}{|c|}{18} & \multicolumn{2}{|c|}{8} & $<0.0001$ \\
\hline Previously used antidepressant medication (\%) & \multicolumn{2}{|c|}{15} & \multicolumn{2}{|c|}{5} & $<0.0001$ \\
\hline History of childhood trauma (\%) & \multicolumn{2}{|c|}{18} & \multicolumn{2}{|c|}{9} & $<0.0001$ \\
\hline
\end{tabular}

with PMS risk. Women with the highest intake of stearic acid (quintile median $=7.4 \mathrm{~g} / \mathrm{d}$ ) had a significant $25 \%$ lower risk of PMS than women with the lowest intake (quintile median $=3.7 \mathrm{~g} / \mathrm{d})\left(95 \%\right.$ CI 0.57, 0.97; $\left.P_{\text {trend }}=0.03\right)$. We did not find intake of other individual fatty acids to be associated with risk.

Dietary intake of stearic acid was strongly correlated with SFA intake ( $r$ 0.93). The inverse association of stearic acid and PMS risk remained after adjustment for SFA; however, due to wider CI the association was no longer significant (RR quintile $5 v$. quintile $1=0 \cdot 67 ; 95 \% \mathrm{CI} 0 \cdot 39,1 \cdot 16$ ). Inclusion of stearic acid in the model for SFA attenuated the results, and the estimates for SFA became null (RR quintile $5 v$. quintile $1=1 \cdot 08$; $95 \%$ CI $0 \cdot 63,1 \cdot 84)$.

The main contributors to stearic acid variation were beef from main dishes and hamburgers, cheese (e.g. Cheddar, American) and chocolate from chocolate bars or other candy bars. The associations between the individual foods and PMS were similar to that of stearic acid and PMS (results not shown).
Results evaluating fat and fatty acid intake at baseline (results not shown), to assess latent effects, were largely similar to those evaluating fat intake at reference year, including results for stearic acid. Women with high intake of stearic acid (quintile median $=7.6 \mathrm{~g} / \mathrm{d}$ ) had $20 \%$ lower risk than those with the lowest intake (quintile median $=4.1 \mathrm{~g} / \mathrm{d} ; 95 \%$ CI $0.61,1.05$; $\left.P_{\text {trend }}=0.04\right)$. However, there were a few exceptions. The $n-3 \mathrm{~s}$ from marine sources, EPA and DHA, showed significant positive associations with PMS, with evidence of linear trend. In fully adjusted models, women with the highest EPA intake at baseline (quintile median $=0 \cdot 12 \mathrm{~g} / \mathrm{d}$ ) had 1.31 times the risk of PMS as those with the lowest (quintile median $=0.01 \mathrm{~g} / \mathrm{d} ; 95 \%$ CI $\left.0.98,1.75 ; P_{\text {trend }}=0.05\right)$. Women with high DHA intake (quintile median $=0.26 \mathrm{~g} / \mathrm{d}$ ) had 1.49 times the risk of PMS as those with the lowest intake (quintile median $=0.05 \mathrm{~g} / \mathrm{d} ; 95 \%$ CI 1.14, 1.95; $P_{\text {trend }}=0.01$ ).

As BMI could potentially lie in the casual pathway of an association between fat intake and PMS risk and could mediate associations, multivariable analyses were repeated without adjusting for BMI in the model; however, estimates were 
Table 2. Quintiles of dietary fat subtypes $2-4$ years before diagnosis and risk of premenstrual syndrome (PMS) ( $n$ 3638): Nurses' Health Study II PMS Sub-Study, 1991-2005

(Relative risks (RR) and 95\% confidence intervals)

\begin{tabular}{|c|c|c|c|c|c|c|c|c|}
\hline & \multirow[b]{2}{*}{ Median (g/d) } & \multirow[b]{2}{*}{ Case:control ratio } & \multicolumn{2}{|c|}{ Age-adjusted } & \multicolumn{2}{|c|}{ Model $1^{*}$} & \multicolumn{2}{|c|}{ Model 2† } \\
\hline & & & $\mathrm{RR}$ & $95 \% \mathrm{Cl}$ & $\mathrm{RR}$ & $95 \% \mathrm{Cl}$ & $\mathrm{RR}$ & $95 \% \mathrm{Cl}$ \\
\hline \multicolumn{9}{|l|}{ Total fat } \\
\hline Q1 & $46 \cdot 4$ & 228:506 & 1 & Ref. & 1 & Ref. & & \\
\hline Q2 & 55.6 & $256: 502$ & 1.13 & $0.91,1.41$ & 1.07 & $0.84,1.35$ & & \\
\hline Q3 & $62 \cdot 3$ & $258: 509$ & $1 \cdot 13$ & $0.91,1.40$ & 1 & $0.79,1.27$ & & \\
\hline Q4 & $68 \cdot 2$ & $234: 470$ & 1.11 & $0.89,1.39$ & 0.91 & $0.71,1.17$ & & \\
\hline Q5 & $76 \cdot 8$ & $246: 429$ & 1.29 & $1.03,1.61$ & 0.95 & $0.73,1.23$ & & \\
\hline $\begin{array}{l}P_{\text {trend }} \\
\text { SFA }\end{array}$ & & & \multicolumn{2}{|c|}{0.05} & \multicolumn{2}{|r|}{0.43} & & \\
\hline Q1 & $15 \cdot 1$ & $235: 440$ & 1 & Ref. & 1 & Ref. & 1 & Ref. \\
\hline Q2 & $18 \cdot 9$ & 242:525 & 0.85 & $0.68,1.06$ & 0.81 & $0.64,1.03$ & 0.74 & $0.57,0.97$ \\
\hline Q3 & 21.6 & $249: 536$ & 0.86 & $0.69,1.07$ & 0.77 & $0.60,0.98$ & 0.67 & $0.49,0.91$ \\
\hline Q4 & $24 \cdot 3$ & 260:472 & 1.01 & $0.81,1.26$ & 0.86 & $0.67,1 \cdot 10$ & 0.74 & $0.53,1.03$ \\
\hline Q5 & $28 \cdot 1$ & $236: 443$ & 0.98 & $0.78,1.22$ & 0.75 & $0.58,0.98$ & 0.63 & $0.44,092$ \\
\hline $\begin{array}{l}P_{\text {trend }} \\
\text { PUFA }\end{array}$ & & & \multicolumn{2}{|c|}{0.65} & \multicolumn{2}{|c|}{0.07} & \multicolumn{2}{|r|}{0.05} \\
\hline Q1 & $7 \cdot 8$ & $247: 540$ & 1 & Ref. & 1 & Ref. & 1 & Ref. \\
\hline Q2 & 9.6 & $245: 474$ & $1 \cdot 14$ & $0.92,1.42$ & $1 \cdot 13$ & $0.89,1.43$ & 1.13 & $0.89,1.44$ \\
\hline Q3 & $10 \cdot 8$ & $229: 484$ & 1.03 & $0.83,1.29$ & 0.98 & $0.77,1.25$ & 0.99 & $0.77,1.28$ \\
\hline Q4 & $12 \cdot 2$ & $251: 490$ & $1 \cdot 15$ & $0.93,1.42$ & $1 \cdot 11$ & $0.87,1.40$ & 1.12 & $0.86,1.45$ \\
\hline Q5 & 14.5 & $250: 428$ & 1.33 & $1.07,1.66$ & $1 \cdot 13$ & $0.89,1.45$ & 1.14 & $0.87,1.50$ \\
\hline $\begin{array}{l}P_{\text {trend }} \\
\text { MUFA }\end{array}$ & & & \multicolumn{2}{|c|}{0.02} & \multicolumn{2}{|r|}{0.39} & \multicolumn{2}{|r|}{0.41} \\
\hline Q1 & $17 \cdot 0$ & 233:502 & 1 & Ref. & 1 & Ref. & 1 & Ref. \\
\hline Q2 & 21.0 & $251: 523$ & 1.04 & $0.83,1.29$ & 0.97 & $0.77,1.24$ & 1.11 & $0.84,1.47$ \\
\hline Q3 & $23 \cdot 8$ & 261:505 & $1 \cdot 12$ & $0.90,1.39$ & 0.99 & $0.78,1.26$ & 1.19 & $0.86,1.64$ \\
\hline Q4 & $26 \cdot 4$ & $236: 462$ & $1 \cdot 12$ & $0.89,1.39$ & 0.92 & $0.72,1.19$ & $1 \cdot 13$ & $0.78,1.64$ \\
\hline Q5 & $30 \cdot 4$ & $241: 424$ & 1.25 & $1.00,1.56$ & 0.97 & $0.74,1.26$ & $1 \cdot 21$ & $0.80,1.84$ \\
\hline $\begin{array}{c}P_{\text {trend }} \\
\text { Trans-fat }\end{array}$ & & & \multicolumn{2}{|c|}{0.04} & \multicolumn{2}{|c|}{0.7} & \multicolumn{2}{|r|}{0.42} \\
\hline Q1 & 1.7 & 218:457 & 1 & Ref. & 1 & Ref. & 1 & Ref. \\
\hline Q2 & $2 \cdot 3$ & $242: 481$ & 1.04 & $0.83,1.30$ & 1.09 & $0.85,1.40$ & $1 \cdot 16$ & $0.90,1.51$ \\
\hline Q3 & $2 \cdot 9$ & 243:498 & 1.01 & $0.81,1.26$ & 0.98 & $0.76,1.25$ & 1.05 & $0.80,1.38$ \\
\hline Q4 & 3.5 & $270: 526$ & 1.06 & $0.85,1.32$ & 0.95 & $0.74,1.23$ & 1.03 & $0.78,1.38$ \\
\hline Q5 & 4.5 & $249: 454$ & $1 \cdot 14$ & $0.91,1.42$ & 1.01 & $0.78,1.32$ & 1.09 & $0.79,1.49$ \\
\hline$P_{\text {trend }}$ & & & & 25 & & .74 & & 0.91 \\
\hline
\end{tabular}

Ref., referent values.

* Model 1 adjusted for age in 1991 (continuous), reference year (1991-1992, 1993, 1994-1996, 1997-1998, 1999-2000, 2001-2002, 2003-2004), age at menarche (continuous), current BMI $\left(\leq 19 \cdot 9,20 \cdot 0-22 \cdot 4,22 \cdot 5-24 \cdot 9,25 \cdot 0-27 \cdot 4,27 \cdot 5-29 \cdot 9, \geq 30 \mathrm{~kg} / \mathrm{m}^{2}\right)$, physical activity $(<3,3-8,9-17,18-26,27-41$, $\geq 42$ metabolic equivalents), duration of oral contraceptive use (none, 1-23, 24-71, 72-119, $\geq 120$ months), parity (nulliparous, 1-2, 3-4, $\geq 5$ pregnancies $>6$ months), smoking (never, past $1-14$, past $15-34$, past $35+$, current $1-14$, current $15-34$, current $35+$ cigarettes/d), previous use of antidepressants (never, ever), childhood trauma score (5, 6-10,11-15, 16-20, 21-25), previous diagnosis of depression (never, ever) and quintiles of total intake of vitamins $\mathrm{B}_{6}, \mathrm{~B}_{1}$, Fe and $\mathrm{Ca} 2-4$ years before reference year.

† Model 2 adjusted for factors included in model $1+$ mutually adjusted for other fat subtypes.

unchanged. Analyses stratified by age and smoking status did not suggest effect modification by any of these factors and there were no significant interactions.

\section{Discussion}

We did not find intake of total fat to be associated with risk of developing PMS. High intake of SFA, specifically stearic acid, was significantly associated with lower risk. Other individual fatty acids, including $n-3$ fatty acids, were not consistently associated with risk.

Few studies have comprehensively assessed how fat and fatty acid intake may be related to PMS. In addition, to date no studies have prospectively assessed fat or fatty acid intake and risk of developing PMS. Prior research of the relation between fat intake and PMS has been limited to consideration of symptom presence and/or severity, rather than risk of developing
PMS. Both Nagata et al. ${ }^{(9)}$ and Gold et al. ${ }^{(10)}$ assessed total fat intake with premenstrual symptoms using cross-sectional study designs. Nagata et al. $^{(9)}$ examined whether total fat and fat subtypes were associated with the severity of premenstrual symptoms among 189 female Japanese students aged 19-34 years ${ }^{(9)}$. Total fat, SFA and MUFA were associated with higher overall symptom severity in the premenstrual phase as well as pain severity specifically. In contrast, in the Study of Women's Health Across the Nation, Gold et al. ${ }^{(10)}$ found total fat intake to be associated with lower cravings/bloating symptoms in older premenopausal US women, but unrelated to the other symptoms assessed, including back pain/cramps, breast pain or headaches.

The inconsistencies in the findings among these studies may be due to several possible reasons: differences in population characteristics such as age and food sources in different geographical reasons, and study design characteristics (i.e. prevalent 
Table 3. Quintiles of dietary fat sources $2-4$ years before reference year and risk of premenstrual syndrome (PMS) ( $n$ 3638): Nurses' Health Study II PMS Sub-Study, 1991-2005

(Relative risks (RR) and $95 \%$ confidence intervals)

\begin{tabular}{|c|c|c|c|c|c|c|c|c|}
\hline & \multirow[b]{2}{*}{ Median $(\mathrm{g} / \mathrm{d})$} & \multirow[b]{2}{*}{ Case:control ratio } & \multicolumn{2}{|c|}{ Age-adjusted } & \multicolumn{2}{|c|}{ Model $1^{*}$} & \multicolumn{2}{|c|}{ Model $2 \dagger$} \\
\hline & & & $\mathrm{RR}$ & $95 \% \mathrm{Cl}$ & $\mathrm{RR}$ & $95 \% \mathrm{Cl}$ & $\mathrm{RR}$ & $95 \% \mathrm{Cl}$ \\
\hline \multicolumn{9}{|l|}{ Animal fat } \\
\hline Q1 & $21 \cdot 7$ & $243: 466$ & 1 & Ref. & 1 & Ref. & 1 & Ref. \\
\hline Q2 & 28.9 & 228:504 & 0.85 & $0.68,1.06$ & 0.78 & $0.61,0.99$ & 0.78 & $0.61,0.99$ \\
\hline Q3 & 33.6 & $260: 524$ & 0.93 & $0.75,1.16$ & 0.81 & $0.64,1.03$ & 0.82 & $0.64,1.05$ \\
\hline Q4 & 38.7 & $259: 488$ & 1 & $0.81,1.24$ & 0.86 & $0.67,1.09$ & 0.85 & $0.66,1.11$ \\
\hline Q5 & $46 \cdot 9$ & $232: 434$ & 1.01 & $0.81,1.26$ & 0.79 & $0.61,1.02$ & 0.77 & $0.58,1.03$ \\
\hline$P_{\text {trend }}$ & & & \multicolumn{2}{|r|}{0.53} & \multicolumn{2}{|r|}{0.17} & \multicolumn{2}{|r|}{0.18} \\
\hline \multicolumn{9}{|l|}{ Dairy fat } \\
\hline Q1 & 5.9 & $192: 375$ & 1 & Ref. & 1 & Ref. & 1 & Ref. \\
\hline Q2 & 9.5 & $246: 456$ & 1.04 & $0.82,1.31$ & 1.06 & $0.82,1.37$ & 1.09 & $0.84,1.42$ \\
\hline Q3 & 12 & 263:505 & 0.98 & $0.78,1.24$ & 1.02 & $0.78,1.32$ & 1.07 & $0.82,1.40$ \\
\hline Q4 & $15 \cdot 1$ & 263:568 & 0.87 & $0.70,1 \cdot 10$ & 0.88 & $0.68,1.15$ & 0.94 & $0.72,1.24$ \\
\hline Q5 & $20 \cdot 5$ & $258: 512$ & 0.95 & $0.75,1.20$ & 1.01 & $0.77,1.32$ & $1 \cdot 11$ & $0.82,1.50$ \\
\hline$P_{\text {trend }}$ & & & \multirow{2}{*}{\multicolumn{2}{|c|}{0.33}} & \multirow{2}{*}{\multicolumn{2}{|c|}{0.68}} & \multirow{2}{*}{\multicolumn{2}{|c|}{0.81}} \\
\hline Vegetable fat & & & & & & & & \\
\hline Q1 & $18 \cdot 2$ & 229:491 & 1 & Ref. & 1 & Ref. & 1 & Ref. \\
\hline Q2 & $23 \cdot 3$ & $246: 510$ & 1.05 & $0.84,1.31$ & 0.97 & $0.76,1.23$ & 0.97 & $0.76,1.23$ \\
\hline Q3 & $27 \cdot 4$ & $241: 491$ & 1.05 & $0.84,1.31$ & 1.04 & $0.81,1.32$ & 1.04 & $0.81,1.32$ \\
\hline Q4 & 31.2 & $260: 477$ & 1.2 & $0.96,1.49$ & 1.08 & $0.85,1.38$ & 1.08 & $0.85,1.39$ \\
\hline Q5 & 37.9 & $246: 447$ & 1.23 & $0.98,1.53$ & 1.04 & $0.81,1.34$ & 1.02 & $0.79,1.31$ \\
\hline$P_{\text {trend }}$ & & & \multicolumn{2}{|r|}{0.03} & \multicolumn{2}{|r|}{0.54} & \multicolumn{2}{|r|}{0.65} \\
\hline
\end{tabular}

Ref., referent values.

* Model 1 adjusted for age in 1991 (continuous), reference year (1991-1992, 1993, 1994-1996, 1997-1998, 1999-2000, 2001-2002, 2003-2004), age at menarche (continuous), current BMI $\left(\leq 19 \cdot 9,20 \cdot 0-22 \cdot 4,22 \cdot 5-24 \cdot 9,25 \cdot 0-27 \cdot 4,27 \cdot 5-29 \cdot 9, \geq 30 \mathrm{~kg} / \mathrm{m}^{2}\right)$, physical activity $(<3,3-8,9-17,18-26,27-41$, $\geq 42$ metabolic equivalents), duration of oral contraceptive use (none, 1-23, 24-71, 72-119, $\geq 120$ months), parity (nulliparous, 1-2, 3-4, $\geq 5$ pregnancies $>6$ months), smoking (never, past 1-14, past 15-34, past 35+, current 1-14, current 15-34, current 35+ cigarettes/d), previous use of antidepressants (never, ever), childhood trauma score $(5,6-10,11-15,16-20,21-25)$, previous diagnosis of depression (never, ever) and quintiles of total intake of vitamins $\mathrm{B}_{6}, \mathrm{~B}_{1}, \mathrm{Fe}$ and $\mathrm{Ca} 2-4$ years before reference year.

† Model 2 adjusted for factors included in model $1+$ mutually adjusted for other fat subtypes (quintiles).

symptoms $v$. incident cases, cross-sectional $v$. prospective). In cross-sectional studies assessing PMS symptoms, temporality cannot be established. It is unclear whether symptomatic women consume foods with higher fat content due to cravings, in order to alleviate symptoms, or whether higher intakes of fat are physiologically involved in the development of premenstrual symptoms.

SFA was inversely associated with the risk of developing PMS in our study, and the association appeared to be largely attributable to stearic acid. The biological mechanism for this is unclear. Although the Dietary Guidelines for Americans suggests limited SFA to $<10 \%$ of total $\mathrm{kcal} / \mathrm{d}$ due to adverse health effects $^{(36)}$, laboratory and clinical evidence suggests that stearic acid may be physiologically different from other SFA ${ }^{(37-40)}$. For example, stearic acid appears to have a neutral effect or may even lower cholesterol levels as opposed to increasing levels ${ }^{(37,38)}$, and may potentially lower risk of breast cancer ${ }^{(39)}$ and $\mathrm{CVD}^{(38)}$. A common source of stearic acid is cocoa butter, which is a primary component of chocolate ${ }^{(40)}$. Many women report chocolate cravings premenstrually and may increase chocolate intake to improve symptoms ${ }^{(41)}$. In post hoc analyses, we evaluated whether chocolate intake may explain the association between stearic acid and PMS risk. When we adjusted for chocolate intake the relationship was slightly attenuated (RR quintile $5 v$. quintile $1=0.80 ; 95 \% \mathrm{CI} 0 \cdot 60,1 \cdot 07$ ), suggesting that chocolate explained some but not all of the observed association with stearic acid. As no other studies have evaluated the relationship between stearic acid and PMS, additional studies specifically evaluating whether stearic acid intake may reduce
PMS risk or be beneficial in treating premenstrual symptoms are warranted along with examining physiological mechanisms.

Several clinical trials have tested the efficacy of treating premenstrual symptoms with fatty acid supplements. Clinical trials of supplementation with $n$-3s, a mixture of PUFA ( $\gamma$-linolenic acid (18:3n-6), oleic, linoleic, other PUFA and vitamin $\mathrm{E})^{(13)}$, and krill oil (high in $n-3)^{(12)}$ have suggested that these supplements can alleviate premenstrual symptoms. Doses and durations of supplementation varied; Sohrabi used $2 \mathrm{~g}$ of $n-3$ for one full cycle and then only during the late luteal phase for two cycles $^{(11)}$. Filho used $1-2 \mathrm{~g}$ of the PUFA for 6 months ${ }^{(13)}$, and Sampalis compared $2 \mathrm{~g}$ of krill oil with $2 \mathrm{~g}$ fish oil for one full cycle then during the late luteal phase for two more cycles ${ }^{(12)}$. These doses are comparable with our highest quintile of intake for $n$-3. However, our study did not find an association with risk of PMS for PUFA, oleic, linoleic or $n-3$ fatty acids. In addition, there was very little supplement use of fish oil or cod liver oil in our study.

We were unable to use prospective symptom charting to assess incident PMS in our large, ongoing prospective cohort. However, we used strict criteria to classify PMS cases and controls, excluding women in the middle of the symptom spectrum and thus reducing the likelihood of misclassification of cases as controls and vice-versa. Women who experience severe symptoms each month and women who experience no symptoms or very minimal symptoms are likely to accurately recall symptom experience and unlikely to be misclassified between the two groups ${ }^{(27)}$. In addition, in a previous validation 
Table 4. Quintiles of fatty acids 2-4 years before reference year and risk of premenstrual syndrome (PMS) ( $n$ 3638): Nurses' Health Study II PMS Sub-Study, 1991-2005

(Relative risks (RR) and $95 \%$ confidence intervals)

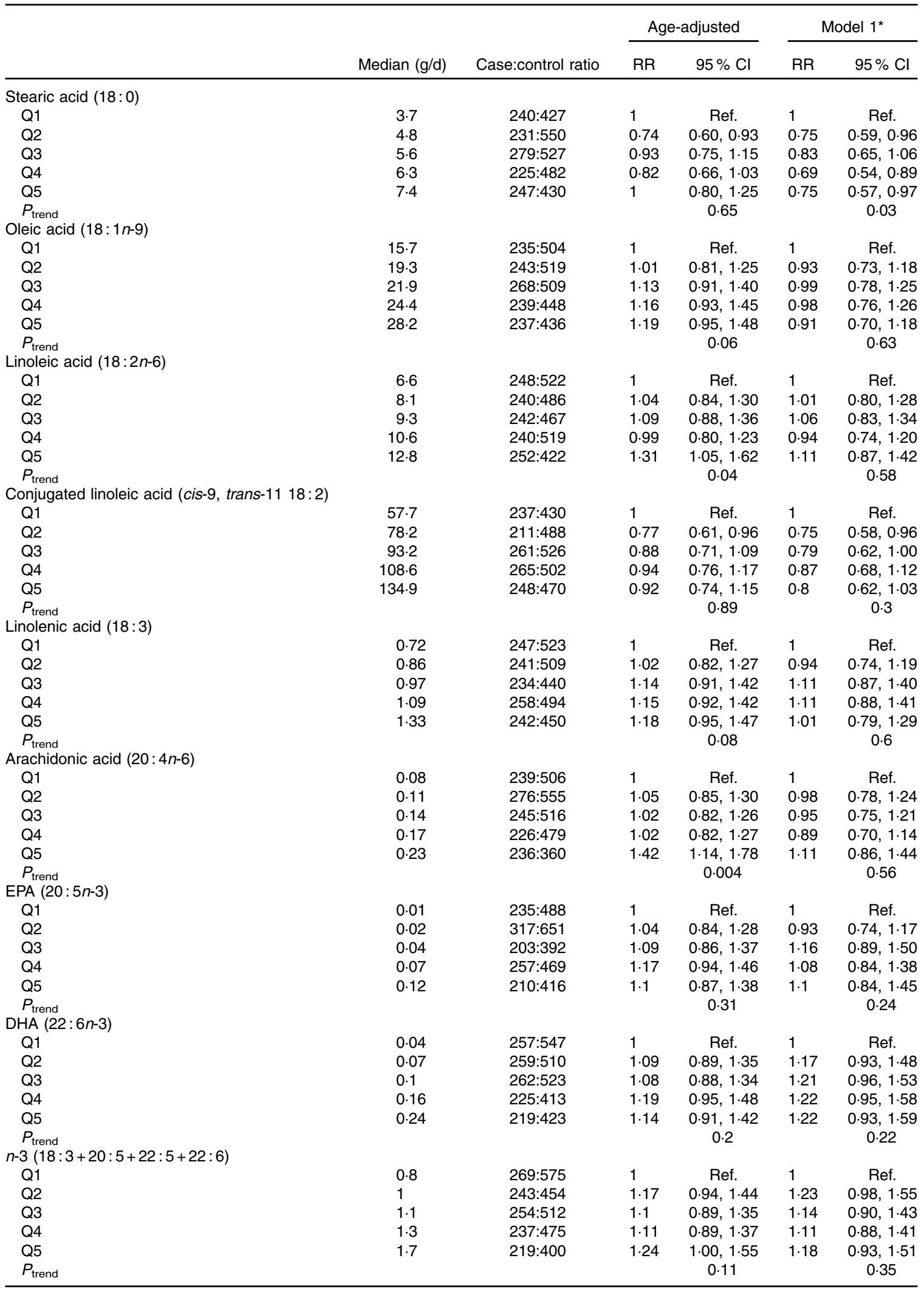


Table 4. Continued

\begin{tabular}{|c|c|c|c|c|c|c|}
\hline & \multirow[b]{2}{*}{ Median (g/d) } & \multirow[b]{2}{*}{ Case:control ratio } & \multicolumn{2}{|c|}{ Age-adjusted } & \multicolumn{2}{|c|}{ Model $1^{*}$} \\
\hline & & & $\mathrm{RR}$ & $95 \% \mathrm{Cl}$ & $\mathrm{RR}$ & $95 \% \mathrm{Cl}$ \\
\hline \multicolumn{7}{|c|}{$n-6($ cis-18:2+20:4) } \\
\hline Q1 & 6.9 & $232: 527$ & 1 & Ref. & 1 & Ref. \\
\hline Q2 & 8.3 & $244: 475$ & $1 \cdot 19$ & $0.96,1.48$ & 1.12 & $0.88,1.42$ \\
\hline Q3 & 9.5 & 249:511 & $1 \cdot 12$ & $0.90,1.39$ & 1.04 & $0.82,1.32$ \\
\hline Q4 & $10 \cdot 8$ & $236: 477$ & $1 \cdot 15$ & $0.92,1.43$ & 1.09 & $0.86,1.39$ \\
\hline Q5 & $13 \cdot 2$ & $261: 426$ & 1.46 & $1 \cdot 17,1 \cdot 82$ & 1.2 & $0.94,1.53$ \\
\hline$P_{\text {trend }}$ & & & & 0.002 & & 0.2 \\
\hline \multicolumn{7}{|l|}{$n-6: n-3$} \\
\hline Q1 & $6 \cdot 2$ & $211: 420$ & 1 & Ref. & 1 & Ref. \\
\hline Q2 & 7.5 & $224: 477$ & 0.93 & $0.74,1.17$ & 0.84 & $0.65,1.08$ \\
\hline Q3 & $8 \cdot 3$ & $246: 480$ & 1.01 & $0.81,1.27$ & 0.94 & $0.73,1.21$ \\
\hline Q4 & $9 \cdot 3$ & $285: 538$ & 1.03 & $0.82,1.28$ & 0.92 & $0.71,1 \cdot 18$ \\
\hline Q5 & $11 \cdot 2$ & $256: 501$ & 0.99 & $0.79,1.24$ & 0.85 & $0.66,1.11$ \\
\hline$P_{\text {trend }}$ & & & & 0.81 & & 0.39 \\
\hline
\end{tabular}

study our method of classifying PMS cases was found to be comparable with methods additionally using report of prospective symptom charting as part of clinical diagnosis ${ }^{(28)}$.

Participants may either over-report or under-report their intake of foods containing fats or fatty acids either unintentionally or purposefully due to beliefs about what they should be eating, thus misclassification is likely. However, because dietary intake was collected prospectively, any misclassification of fat or fatty acid intake, therefore would not be related to PMS status and would likely bias result to the null. Moreover, previous validation studies have found fat intakes from FFQ data to be reasonably well correlated with diet record $(r>0.41)^{(30)}$ and several previous studies within the NHS2 suggest that FFQ are sensitive enough to detect associations between fats and outcomes such as endometriosis or CVD at similar ranges of intake ${ }^{(42,43)}$. Lastly, the range of intake for total fat and subtypes of fat (i.e. SFA, MUFA, PUFA and trans-fat) within our study was comparable with previous observational studies of $\mathrm{PMS}^{(9,10)}$.

Overall, we did not find intake of dietary fats to be associated with higher risk of developing PMS, though high intake of stearic acid was associated with a statistically significant lower risk of PMS. As this is the first study to suggest this association and the fact that these findings may be by chance due to multiple testing, additional prospective studies are needed to further evaluate whether stearic acid may reduce risk of developing PMS or improve existing symptoms taking into account any potential adverse effects.

\section{Acknowledgements}

The authors thank the participants and staff of the NHS2 for their valuable contributions.

The NHS2 cohort is supported by the NIH grant CA176726. E. R. B.-J. was supported by National Institutes of Health, Department of Health and Human Services grant MH076274; a cy pres distribution from Rexall/Cellasene settlement litigation; and a grant from GlaxoSmithKline Consumer Healthcare.

J. E. M., S. E. H. and E. R. B.-J. designed the research; S. C. H. and E. R. B.-J. conducted the research; J. E. M. and S. E. H. provided essential materials; S. C. H. and E. R. B.-J. performed the statistical analysis; S. C. H. and E. R. B.-J. wrote the paper; B. W. W., L. M. T. and C. B. interpreted study results, reviewed manuscript for important intellectual content and contributed knowledge of underlying biologic mechanisms; S. C. H., J. E. M. and E. R. B-J. had primary responsibility for the final content. All authors read and approved the final manuscript.

The authors declare that there are no conflicts of interest.

\section{References}

1. Rapkin AJ \& Winer SA (2009) Premenstrual syndrome and premenstrual dysphoric disorder: quality of life and burden of illness. Expert Rev Pharmacoecon Outcomes Res 9 , 157-170.

2. O'Brien S, Rapkin A, Dennerstein L, et al. (2011) Diagnosis and management of premenstrual disorders. BMJ 342, d2994.

3. Johnson SR (1987) The epidemiology and social impact of premenstrual symptoms. Clin Obstet Gynecol 30, 367-376.

4. Halbreich U, Borenstein J, Pearlstein T, et al. (2003) The prevalence, impairment, impact, and burden of premenstrual dysphoric disorder (PMS/PMDD). Psychoneuroendocrinology 28, Suppl. 3, 1-23.

5. Chocano-Bedoya PO \& Bertone-Johnson ER (2013) Premenstrual syndrome. In Women Health, 2nd ed. pp. 179-191 [MB Goldman, R Troisi and KM Rexrode, editors]. Amsterdam: Elsevier/Academic Press.

6. Bertone-Johnson ER, Whitcomb BW, Rich-Edwards JW, et al. (2015) Premenstrual syndrome and subsequent risk of hypertension in a prospective study. Am J Epidemiol 182, 1000-1009.

7. The American College of Obstetricians and Gynecologists (2011) Frequently asked questions FAQ057 gynecologic problems, premenstrual syndrome. https://www.acog.org/ / media/For\%20Patients/faq057.pdf (accessed April 2017). 
8. Houghton S \& Bertone-Johnson ER (2015) Macronutrients and premenstrual syndrome. In Advances in Medicine and Biology, vol. 87, pp. 137-156 [LV Berhardt, editor]. Hauppauge, NY: NOVA Science Publishers, Inc.

9. Nagata C, Hirokawa K, Shimizu N, et al. (2004) Soy, fat and other dietary factors in relation to premenstrual symptoms in Japanese women. BJOG 111, 594-599.

10. Gold EB, Bair Y, Block G, et al. (2007) Diet and lifestyle factors associated with premenstrual symptoms in a racially diverse community sample: Study of Women's Health Across the Nation (SWAN). J. Womens Health (Larchmt) 16, 641-656.

11. Sohrabi N, Kashanian M, Ghafoori SS, et al. (2013) Evaluation of the effect of omega- 3 fatty acids in the treatment of premenstrual syndrome: 'a pilot trial'. Complement Ther Med 21, 141-146.

12. Sampalis F, Bunea R, Pelland MF, et al. (2003) Evaluation of the effects of Neptune Krill Oil on the management of premenstrual syndrome and dysmenorrhea. Altern Med Rev J Clin Ther 8, 171-179.

13. Rocha Filho EA, Lima JC, Pinho Neto JS, et al. (2011) Essential fatty acids for premenstrual syndrome and their effect on prolactin and total cholesterol levels: a randomized, double blind, placebo-controlled study. Reprod Health 8, 2 .

14. Watanabe S, Sakurada M, Tsuji H, et al. (2005) Efficacy of $\gamma$-linolenic acid for treatment of premenstrual syndrome, as assessed by a prospective daily rating system. J Oleo Sci $\mathbf{5 4}$, 217-224.

15. Budeiri D, Li Wan Po A \& Dornan JC (1996) Is evening primrose oil of value in the treatment of premenstrual syndrome? Control Clin Trials 17, 60-68.

16. Aeberli I, Molinari L, Spinas G, et al. (2006) Dietary intakes of fat and antioxidant vitamins are predictors of subclinical inflammation in overweight Swiss children. Am J Clin Nutr 84, 748-755.

17. Santos S, Oliveira A \& Lopes C (2013) Systematic review of saturated fatty acids on inflammation and circulating levels of adipokines. Nutr Res 33, 687-695.

18. Turunen AW, Jula A, Suominen AL, et al. (2013) Fish consumption, omega-3 fatty acids, and environmental contaminants in relation to low-grade inflammation and early atherosclerosis. Environ Res 120, 43-54.

19. Rangel-Huerta OD, Aguilera CM, Mesa MD, et al. (2012) Omega-3 long-chain polyunsaturated fatty acids supplementation on inflammatory biomakers: a systematic review of randomised clinical trials. Br J Nutr 107, Suppl. 2, S159-S170.

20. Calder PC (2006) Polyunsaturated fatty acids and inflammation. Prostaglandins Leukot Essent Fatty Acids 75, 197-202.

21. Bertone-Johnson ER, Ronnenberg AG, Houghton SC, et al. (2014) Association of inflammation markers with menstrual symptom severity and premenstrual syndrome in young women. Hum Reprod 29, 1987-1994.

22. Gold EB, Wells C \& Rasor MO (2016) The association of inflammation with premenstrual symptoms. $J$ Womens Health (Larchmt) 25, 865-874.

23. Puder JJ, Blum CA, Mueller B, et al. (2006) Menstrual cycle symptoms are associated with changes in low-grade inflammation. Eur J Clin Invest 36, 58-64.

24. Azizieh FY, Alyahya KO \& Dingle K (2017) Association of selfreported symptoms with serum levels of vitamin $\mathrm{D}$ and multivariate cytokine profile in healthy women. J Inflamm Res 10, 19-28.
25. Tsuij M, Tamai Y, Wada K, et al. (2012) Associations of intakes of fat, dietary fiber, soy isoflavones, and alcohol with levels of sex hormones and prolactin in premenopausal Japanese women. Cancer Causes Control 23, 683-689.

26. Bäckström T, Andreen L, Birzniece V, et al. (2003) The role of hormones and hormonal treatments in premenstrual syndrome. CNS Drugs 17, 325-342.

27. Bertone-Johnson ER, Hankinson SE, Bendich A, et al. (2005) Calcium and vitamin D intake and risk of incident premenstrual syndrome. Arch Intern Med 165, 1246-1252.

28. Bertone-Johnson ER, Hankinson SE, Johnson SR, et al. (2007) A simple method of assessing premenstrual syndrome in large prospective studies. J Reprod Med 52, 779-786.

29. Mortola JF, Girton L, Beck L, et al. (1990) Diagnosis of premenstrual syndrome by a simple, prospective, and reliable instrument: the calendar of premenstrual experiences. Obstet Gynecol 76, 302-307.

30. Willett WC (2013) Nutritional Epidemiology, 3rd ed. Oxford; New York: Oxford University Press.

31. Harvard TH. Chan School of Public Health Nutrition Department Food Composition Table. https://regepi.bwh.harvard. edu/health/nutrition/ (accessed April 2017).

32. London SJ, Sacks FM, Caesar J, et al. (1991) Fatty acid composition of subcutaneous adipose tissue and diet in postmenopausal US women. Am J Clin Nutr 54, 340-345.

33. Willett W, Stampfer M, Chu NF, et al. (2001) Assessment of questionnaire validity for measuring total fat intake using plasma lipid levels as criteria. Am J Epidemiol 154, $1107-1112$

34. Sun Q, Ma J, Campos H, et al. (2007) Comparison between plasma and erythrocyte fatty acid content as biomarkers of fatty acid intake in US women. Am J Clin Nutr 86, 74-81.

35. Bertone-Johnson ER, Whitcomb BW, Missmer SA, et al. (2014) Early life emotional, physical, and sexual abuse and the development of premenstrual syndrome: a longitudinal study. $J$ Womens Health (Larchmt) 23, 729-739.

36. U.S. Department of Health and Human Services \& U.S. Department of Agriculture (2015) 2015-2020 Dietary Guidelines for Americans. https:/health.gov/dietaryguidelines/2015/resources/ 2015-2020_Dietary_Guidelines.pdf (accessed April 2017).

37. Kris-Etherton PM \& Mustad VA (1994) Chocolate feeding studies: a novel approach for evaluating the plasma lipid effects of stearic acid. Am J Clin Nutr 60, 1029S-1036S.

38. Kelly FD, Sinclair AJ, Mann NJ, et al. (2001) A stearic acid-rich diet improves thrombogenic and atherogenic risk factor profiles in healthy males. Eur J Clin Nutr 55, 88-96.

39. Evans LM, Cowey SL, Siegal GP, et al. (2009) Stearate preferentially induces apoptosis in human breast cancer cells. Nutr Cancer 61, 746-753.

40. Ding EL, Hutfless SM, Ding X, et al. (2006) Chocolate and prevention of cardiovascular disease: a systematic review. Nutr Metab (Lond) 3, 2.

41. Rossignol AM \& Bonnlander H (1991) Prevalence and severity of the premenstrual syndrome. Effects of foods and beverages that are sweet or high in sugar content. J Reprod Med 36, 131-136.

42. Missmer SA, Chavarro JE, Malspeis S, et al. (2010) A prospective study of dietary fat consumption and endometriosis risk. Hum Reprod 25, 1528-1535.

43. Oh K, Hu FB, Manson JE, et al. (2005) Dietary fat intake and risk of coronary heart disease in women: 20 years of follow-up of the nurses' health study. Am J Epidemiol 161, 672-679. 